\title{
Adenoviral transgene delivery provides an approach to identifying important molecular processes in inflammation: evidence for heterogenecity in the requirement for $\mathrm{NF} \kappa \mathrm{B}$ in tumour necrosis factor production
}

\author{
Brian M J Foxwell, Jan Bondeson, Fionula Brennan, Marc Feldmann
}

\begin{abstract}
The success of anti-tumour necrosis factor (TNF) treatment, either using antibodies or soluble receptors, has defined TNF as a major factor of the inflammatory response in rheumatoid arthritis (RA). As a result of this success, much attention has been devoted to understanding the molecular mechanisms by which TNF expression and activity is elicited and controlled. By understanding these pathways, it is hoped that key elements of the molecular pathology associated with RA will be uncovered and, as a result, new targets for therapeutic intervention will be identified. However, studying the cell and molecular biology of model systems for RA, such as primary human macrophages, or tissue from rheumatoid joints may present technical problems. In an attempt to overcome this, we have investigated the use of adenovirus as a means of delivering transgenes by which different intracellular pathways can be modulated and examined. Our data show that adenovirus can be successfully used to efficiently deliver transgenes to primary human macrophages and RA joint tissue. Using a virus encoding IкB $\alpha$, the natural inhibitor of NFKB, we show that the requirement for the transcription factor is not universal, but is dependent on the nature of the stimulus. Furthermore, while NFKB is of importance for the expression of TNF and other proinflammatory cytokines (for example, interleukin 6) and the destructive matrix metalloproteinases, this factor is not required for the expression of antiinflammatory cytokines interleukin 10 and interleukin 1 receptor antagonist. (Ann Rheum Dis 2000;59(suppl I):i54-i59)
\end{abstract}

The success of anti-tumour necrosis factor treatment reveals key mechanisms of inflammation in rheumatoid arthritis The success of recent clinical trials with anti-tumour necrosis factor (TNF) treatment in rheumatoid arthritis (RA) has confirmed the prior laboratory findings that TNF was of pivotal importance. ${ }^{1-6}$ Inhibition of TNF leads to downregulation of the expression of many other parameters associated with RA pathology, including other cytokines (for example, interleukin 6 (IL6), matrix metalloproteinases (MMP), integrins, and the angiogenic factor vascular endothelial growth factor $(\mathrm{VEGF}) .^{78}$ To date more than 60000 patients have received anti-TNF treatment, either antibody or soluble receptor, with a significant proportion $(>60 \%)$ showing marked benefit. However, despite the success of this form of treatment, there is still room for improvement on anti-TNF therapy. Besides the expense of producing proteins as therapeutics and the requirement for parenteral administration, the transient effect of anti-TNF therapy does require repeated treatment and long term systemic inhibition of TNF. There are questions what effect this will have on the function of the innate immune system and host anti-microbial defence of which TNF is a key part. Also, there is evidence that TNF may have a key role in the tuning of the adaptive immune system and provide a suppressive signal to $\mathrm{T}$ cell function. ${ }^{910}$ Such a role for TNF in adaptive immunity is supported by the observation that a number of patients receiving anti-TNF treatment have developed lupus-like circulating antibodies against double stranded DNA. Most importantly, there is the problem that a significant proportion of the patients (about $40 \%$ ) fail to respond to anti-TNF treatment. ${ }^{6}$ Obviously, there is still much scope for further analysis of TNF and its role in the pathogenesis of RA and the search for novel therapeutic targets in this disease.

The complex nature of the mechanisms controlling TNF expression

As macrophages are the major producers of TNF and other pro-inflammatory mediators in RA and inflammation in general, these cells can be seen as the immediate proximal stage to TNF in the cascade that leads to inflammation (fig 1). Therefore, understanding the cell and molecular biology of these cells in health and disease could help to answer some of the questions presented above. Investigating the molecular signalling mechanisms that control the production of TNF and other proinflammatory mediators could lead to the identification of targets for future therapeutic intervention. As many elements of signalling pathways are kinases or other enzymes, this would open up the possibility of screening for, or designing, specific low molecular weight inhibitors that could be orally bioavailable and, 


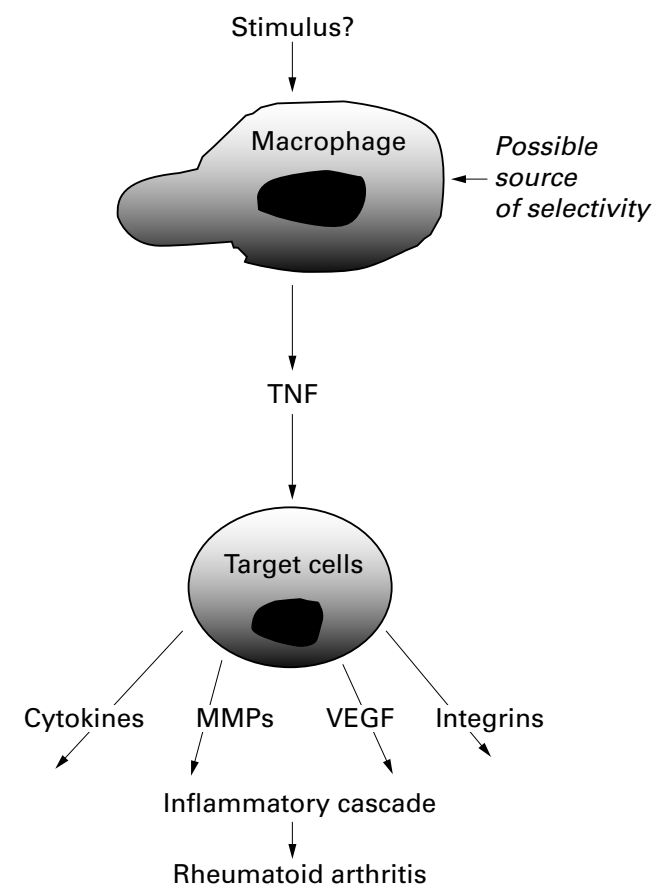

Figure 1 The macrophage, TNF, and the inflammatory response in $R A$. The success of anti-TNF treatments support the view that TNF is important in driving the expression of a number of factors involved in the molecular pathology of $R A$, including cytokines, matrix metalloproteinases (MMPs), integrins and vascular endothelial growth factor (VEGF). Investigating the molecular biology of the macrophage may identify new targets for treatment that may be more selective in effecting TNF expression and be more closely related to the nature of the stimulus.

thus, overcome the problems associated with protein-based therapeutics. In addition, we hypothesised that the intracellular mechanisms that regulate TNF production, even in a given cell type such as the macrophage, may not be uniform and vary with the nature of the stimulus. If so, and the discriminating elements of different TNF inducing pathways could be identified, one could envisage that with an appropriate inhibitor TNF production associated with inflammation could be selectively suppressed while sparing other more benign forms of cytokine production (fig 2). Evidence for alternative signalling mechanisms controlling TNF expression has been published suggesting a differential use of the transcription factor, NFKB. However, in these studies, the requirement for $\mathrm{NF \kappa B}$ seems to segregate between murine macrophages stimulated with lipopolysaccharide (LPS) that required the factor, ${ }^{11}{ }^{12}$ and human lymphocyte cell lines, activated with PMA/ionomycin, which showed no requirement for this transcription factor, but used NFAT instead. ${ }^{13-15}$ Previous studies have shown that the mechanisms controlling TNF production and activity are highly complex (fig 3) with major control mechanisms being applied at gene transcription, by the regulation of transcription factors, and posttranscriptionally and translationally involving the large 3' un-translated region (UTR) of the TNF mRNA. ${ }^{16}$ In addition, TNF is processed post-translationally, being synthesised as a trans-membrane protein that is cleaved from the cell by an ADAM family matrix metalloproteinase, TACE (TNF $\alpha$ converting enzyme). ${ }^{17} 18$ Finally, the biological activity of TNF is controlled by the balance between the concentration of the cytokine and the soluble TNF receptor. However, it must be remembered that the majority of data pertaining to molecular mechanisms controlling TNF production in macrophages, have been derived from studies using LPS as a stimulus and mostly using transformed cell lines of human or murine origin. Because of problems associated with the induction of transgenes (a major approach to signal transduction studies) into primary human monocytes and macrophages, these cell systems have not been so widely explored. Even less studied is RA tissue itself where additional problems, related to the amount of material available and the cellular heterogeneity of the tissue, are present. The potential use of such primary human models are an important consideration, as the stimulus driving TNF production in RA is obscure, the relevance of LPS derived data to the disease is unknown.

\section{Adenovirus provides an efficient means to deliver transgene to macrophages} In an attempt to address some of the problems discussed above, it was felt necessary to develop an efficient means to introduce transgenes into macrophages. Conventional transfection techniques are not very effective in cells of the monocyte-macrophage lineage and even cell lines have proved difficult to transfect with high efficiency. ${ }^{19}$ To overcome problems with

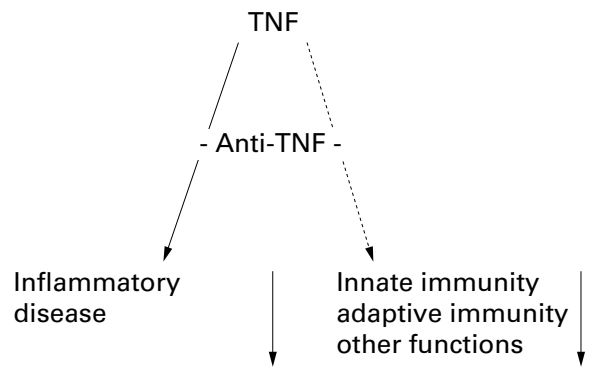

Selective inhibition of TNF by blocking inflammation related production

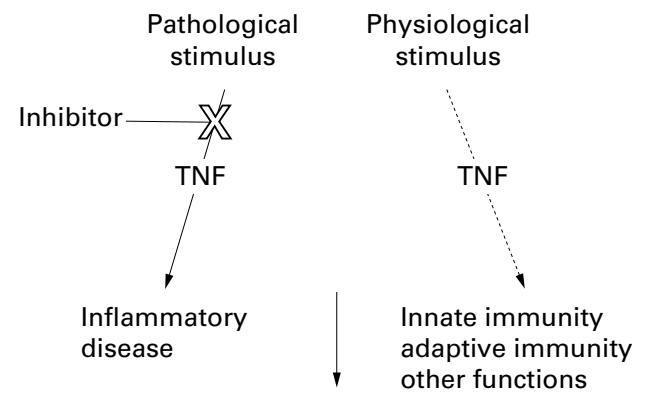

Figure 2 Long term targeting of $T \mathrm{NF}$ - possible problems and solutions. At present anti-TNF strategies provide for a systemic inhibition of TNF function. While inhibiting inflammation in the long term, detrimental effects to physiological systems may occur. Targeting the mechanisms of TNF production may provide an alternative approach that restricts suppression of TNF biology to inflammatory disease, while sparing other, physiological inducers of expression. 


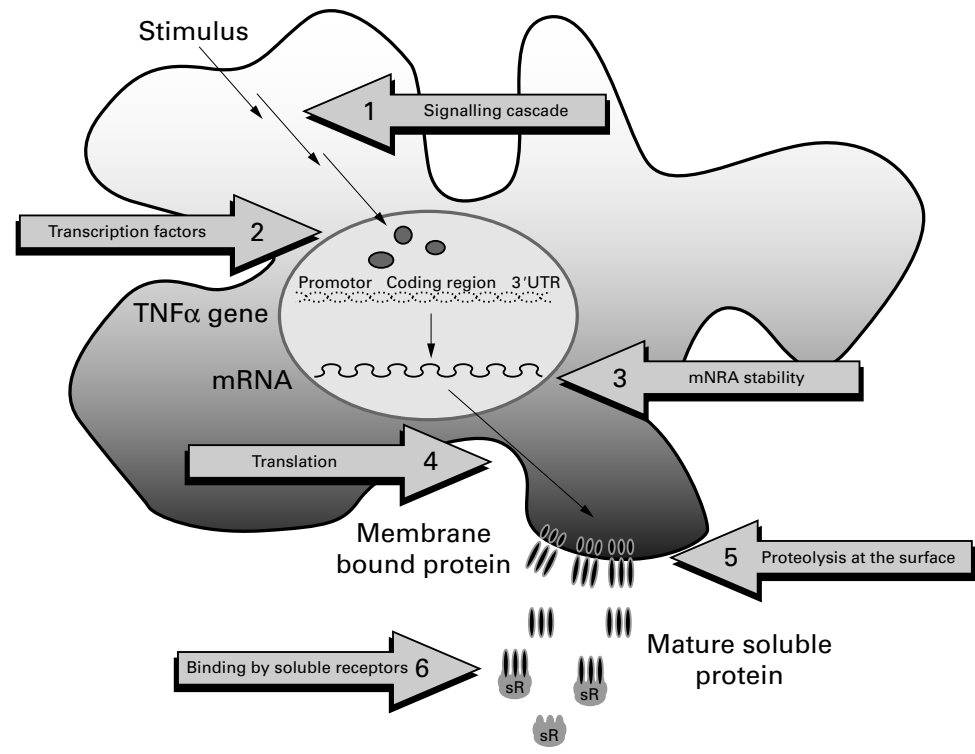

Figures 3 The complex control of TNF expression may provide many targets for intervention. TNF production is controlled at multiple levels. It is possible that any of these could be the source of novel approaches of blocking TNF production. At present soluble receptors (6) is the basis for the successful anti-TNF approach to $R A$ treatment.

low efficiency, permanently transfected cell lines have been derived from macrophage cell lines. However, this approach would not be applicable in human primary monocytes or macrophages as these cells do not proliferate. Moreover, such a strategy would be of no use for RA joint macrophages where the regulation of TNF production has to be studied in the context of other cells ( $\mathrm{T}$ cells and fibroblast) with which the macrophage is in contact within the environment of the inflamed joint. Viral vectors can provide an alternative tool for the introduction of transgenes, as they are very effective in delivering their own genes to cells they infect. Of the two most commonly used systems, retroviruses, although relatively simple, suffer from the drawback that successful infection requires cells to be in cycle, effectively ruling out their use in human macrophages. In contrast, adenoviral vectors can infect both dividing and non-dividing cells. Adenoviral

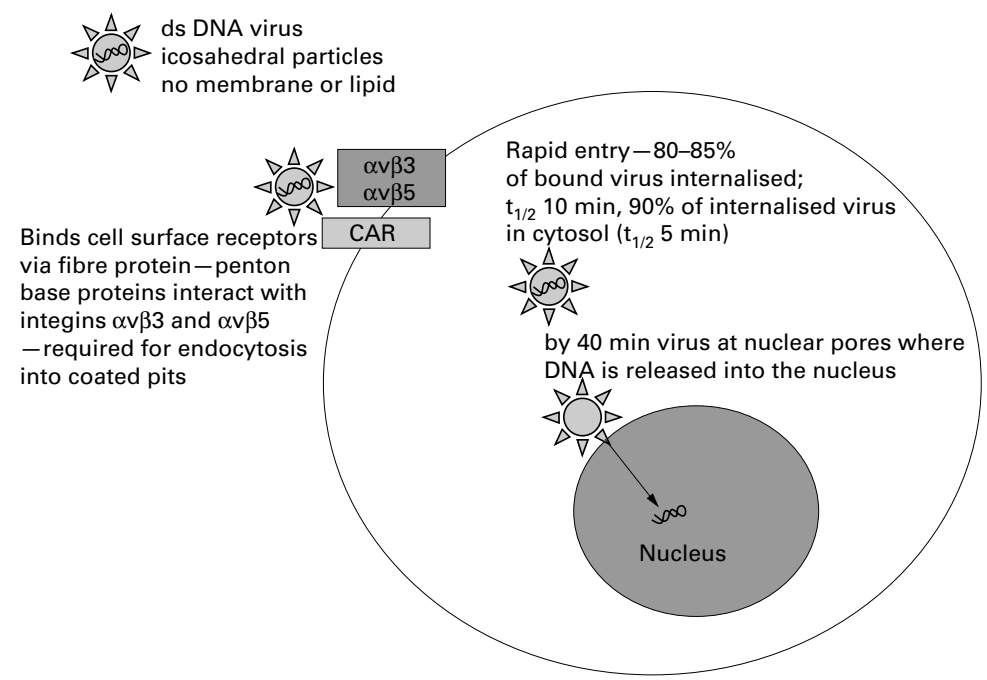

Figure 4 Requirements and efficiency of adenoviral infection. $C A R=$ coxsackie-adenoviral receptor. infection requires cells to express the coxsackie-adenovirus receptor $(\mathrm{CAR})^{20}$ and the $\alpha v \beta 3$ or $\alpha v \beta 5$ integrins as cofactors for viral entry. ${ }^{21-23}$ Entry of the virus into the cell is rapid and the viral genome is delivered directly to the nucleus (fig 4). However, previous attempts to infect monocytes or macrophages have not been very successful, either requiring high ratios of viral particle per cell, (that is, multiplicity of infection (moi)), or achieving low efficiency of infection. ${ }^{21}{ }^{22}$ Using an adenoviral vector encoding $\beta$-galactosidase (Advßgal), we have observed that deriving macrophages from elutriated human primary blood monocytes, by treating cells with macrophage colony stimulating factor (M-CSF) for 48-72 hours, greatly improves the efficiency of adenoviral infection. ${ }^{23}$ This was associated with the upregulation of $\alpha v \beta 5$ integrin expression. Under these circumstances, adenovirus could infect about $95 \%$ of cells at moi of 50 (fig 5 ). Macrophages from RA joints were also highly infectible, without any requirement for M-CSF pretreatment; a moi of 40 of Adv $\beta$ gal resulting in $>95 \%$ infection (fig 5). The high efficiency of adenoviral infection was of great importance as it precludes any need for separating infected from non-infected cells, an important consideration when addressing the mixed culture system of RA joint cells. It was interesting to note that all the cells in the RA synovium were permissive to adenoviral infection, even the RA joint $\mathrm{T}$ cells. ${ }^{24}$ This was a very interesting observation as $\mathrm{T}$ cells are normally highly refractory to adenovirus infection. ${ }^{21}$

\section{Using an IкB $\alpha$ transgene to study the role of NFKB in TNF production in health and disease}

The establishment of conditions for effective delivery of transgenes to macrophages made it possible to study signalling pathways in these cells in a more specific way than before. The availability of a natural inhibitor of $\mathrm{NF} \kappa \mathrm{B}$, in $\mathrm{I} \kappa \mathrm{B} \alpha$, and the previous controversy of the role of this transcription factor in TNF production, provided the ideal system for testing the usefulness of adenoviral vector approaches to the study of intracellular signalling in macrophages. Infection of human primary macrophages with a virus encoding $\operatorname{I\kappa B} \alpha(\operatorname{AdvI} \kappa \mathrm{B} \alpha)$ produced a substantial overexpression of the transgene, compared with uninfected cells or cells infected with an adenovirus containing no insert (Adv0) (fig 6A). Infection with AdvIкB $\alpha$ also resulted in the inhibition of LPS induced NF $\kappa$ B DNA binding activity in the nuclei (fig 6B). Assays of LPS induced TNF production showed $65 \%$ inhibition when macrophages were infected with $\mathrm{AdvI} \mathrm{I} B \alpha$. In contrast, infection with control virus had no effect on TNF production (fig $7 \mathrm{~A}$ ). NFאB binding sites are also found in the promoters of genes for many other proinflammatory cytokines, for example, IL1 and IL6. The effect of NFKB blockade on the expression of these cytokines, after LPS stimulation, was also assessed. Both IL1 and IL6 were inhibited to a similar extent degree to TNF (fig 7A). Macrophages also produce a number of anti-inflammatory factors, IL1 


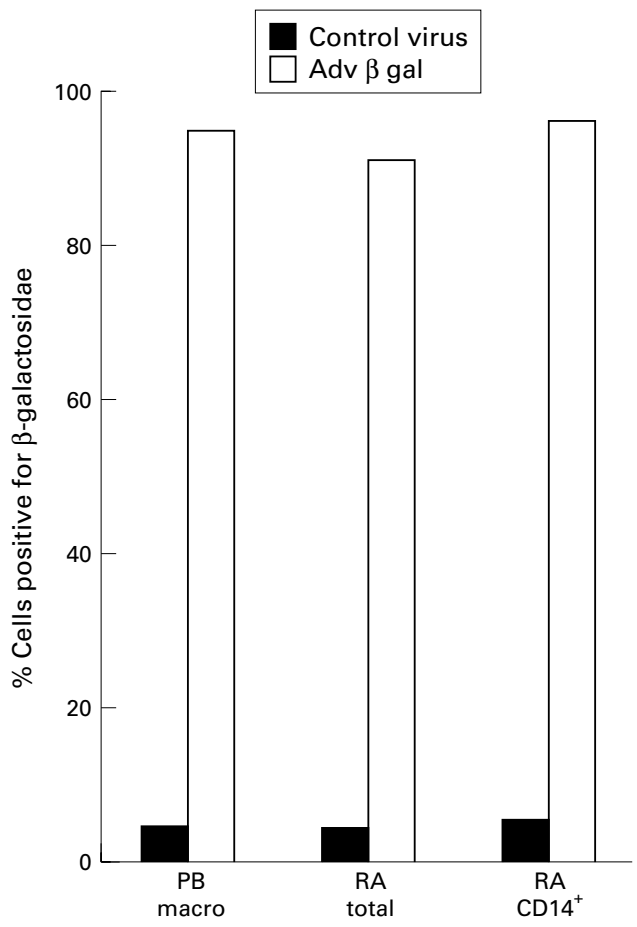

Figure 5 Efficient infection of macrophages from the periphery and $R A$ joint tissue. Macrophages were derived from peripheral blood monocytes by two days pretreatment with $100 \mathrm{ng} / \mathrm{ml} \mathrm{M}-\mathrm{CSF}$, as described previously. ${ }^{23} \mathrm{RA}$ joint tissues were obtained from the synovium from patients with $R A$ undergoing surgery. ${ }^{24}$ Peripheral blood $M-C S F$ macrophages, or RA joint cell cultures were infected with an adenovirus encoding $\beta$-galactosidase (Adv $\beta$-gal, kindly provided by Drs Woods and Byrnes, Oxford, UK) at a moi of 50 or 40 respectively. After 48 hours, cells were analysed for $\beta$-galactosidase expression by FACS. For RA joint cells, immunofluorescence with anti-CD14 antibodies was used to identify the macrophage population. ${ }^{24}$

receptor antagonist (IL1RA), IL10 and soluble(s) TNF receptor(R)s. Although p75 sTNFR expression was inhibited to a similar degree to the proinflammatory cytokines (about $65 \%$ ), LPS induced IL1RA was affected to a lesser extent (35\%) and IL10 hardly at all $(10 \%)$ (fig $7 \mathrm{~A})$. The effect on IL10 turned out to be almost entirely secondary to inhibition of TNF production (not shown). This result agrees with previous observations that the IL10 promoter does not contain any $\mathrm{NF \kappa B}$ binding sites.

A

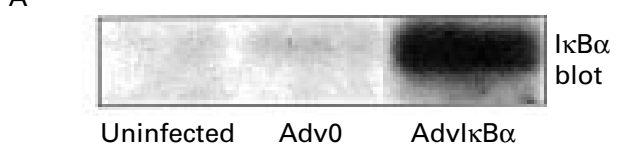

B

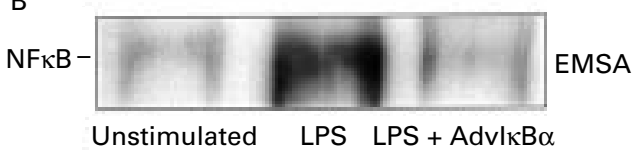

Figure 6 Expression of an adenovirus delivered $I \kappa B a$ transgene in macrophages inhibits NFKB activation. (A) Peripheral blood M-CSF macrophages were either uninfected, or infected with an I $\mathrm{B}$ a encoding adenovirus (AdvI $\kappa B a)$, or control virus Adv0 at moi 40. After 48 hours cells were lysed and cytosolic extracts were examined for $I \kappa B a$ expression by immunoblotting. (B) Cells were either uninfected, or infected with AdvI Ba at moi 40 . After 48 hours the cells where activated with LPS (10 $\mathrm{ng} / \mathrm{ml})$ for 30 minutes followed by nuclear extraction. Nuclear NFKB DNA binding activity was analysed by EMSA.
The requirement for $\mathrm{NF} \kappa \mathrm{B}$ is dependent on the nature of the stimulus

A major question that inspired this study was whether there was heterogeneity in the signalling pathways that are used to induce TNF expression. Macrophages were infected with $\operatorname{Adv} 0$ or $A d v I \kappa B \alpha$ and activated by a variety of stimuli known to induce TNF expression; the yeast product zymosan, anti-CD45 antibodies, phorbol 12-myristate 13-acetate (PMA) and ultraviolet light. PMA and ultraviolet light are both known to induce $\mathrm{NF} \kappa \mathrm{B}$ activation and the expression of TNF induced by both stimulus was effectively inhibited by the overexpression of I $\kappa \mathrm{B} \alpha$ (fig $7 \mathrm{~B})$. In contrast, zymosan, or antiCD45 antibody induced activation of TNF expression was unaffected (fig 7B). We have been unable to demonstrate the activation of NFKB binding activity by either stimulus. ${ }^{25}{ }^{26} \mathrm{It}$ would seem, therefore, that there is diversity in the intracellular signalling mechanisms inducing TNF synthesis, and that both NFKB dependent (LPS, PMA, ultraviolet light), and NFKB independent (zymosan, anti-CD45) exist. We have also observed that anti-CD45 antibodies induces the activation of phosphatidyl inositol 3' kinase in macrophages and that inhibitors of this enzyme, wortmannin and LY294002, inhibit TNF production. ${ }^{26}$ In contrast, we have previously shown that LPS stimulation of TNF expression is stimulated by wortmannin and is unaffected by LY294002. ${ }^{27}$

\section{Adenoviral transgene delivery allows the investigation of signalling mechanisms in RA joint cell cultures}

The data described above demonstrate that the requirement for $\mathrm{NF \kappa B}$ in TNF production is dependent on the nature of the stimulus. As, in a disease like RA, the precise nature of the factor(s) (fig 1) inducing cytokine expression is unknown, such questions can be investigated only by direct examination. To do this, RA joint cell cultures were infected with Adv0 or AdvI $\kappa \mathrm{B} \alpha$. As for LPS stimulated macrophages, TNF production was inhibited by about $70 \%$ (fig $8 \mathrm{~A}$ ), indicating that $\mathrm{NF} \kappa \mathrm{B}$ is an important factor for TNF expression in RA. Moreover, IL6 production was also greatly diminished to a degree similar to that seen in LPS activated cells. However, the inhibition of IL1 production was more moderate (33\%) compared with that of LPS stimulated macrophages. IL8 production was also only moderately effected (about 33\%). Studies on the anti-inflammatory cytokines showed no inhibitory effect of $I \kappa B \alpha$ on IL1RA or IL10 expression and, if anything, a slight enhancement of IL11 expression. In contrast, there was a substantial inhibition of p75 soluble TNF receptor production (fig $8 \mathrm{~A}$ ). These data would indicate that $\mathrm{NF \kappa B}$ is an excellent therapeutic target for RA, because blockade of this transcription factor provides the ideal result, inhibiting the expression of key proinflammatory cytokines, while sparing the major anti-inflammatory mechanisms.

The studies were also extended to investigate the expression of MMPs production by the joint cell cultures. These enzymes are generally considered to be the major players in the 

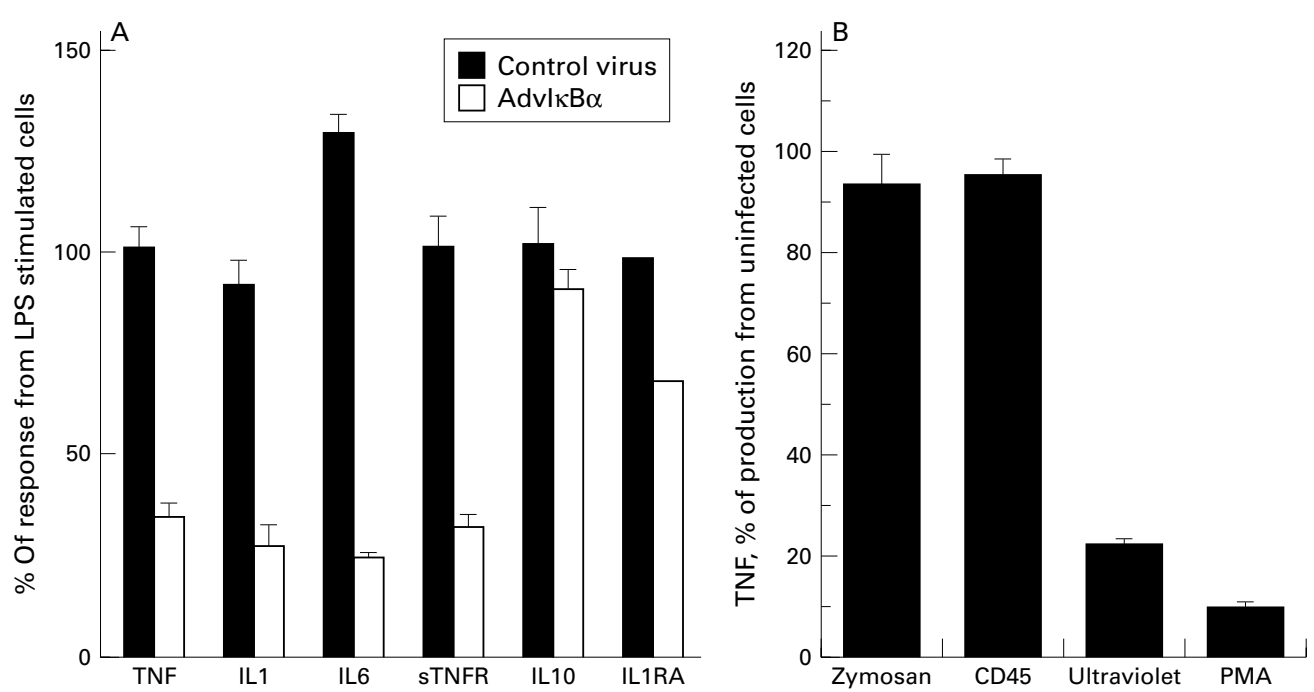

Figure 7 Requirement for $N F \kappa B$ during cytokine production in response to LPS and other stimuli. (A) M-CSF macrophages were treated with control virus (Adv0), or $A d v I \kappa B a$ at moi 40 . After 48 hours cells were activated with 10 ng/ml LPS for 20 hours, after which culture supernatants were harvested and assayed for cytokine production by ELISA. (B) As above, except that AdvIKBa infected macrophages were activated with $30 \mu \mathrm{g} / \mathrm{ml} z y m o s a n, 10 \mu \mathrm{g} / \mathrm{ml}$ anti-CD45 antibodies, $2000 \mathrm{~F}$ ultraviolet light, or $10 \mathrm{nM}$ PMA for 20 hours, followed by assaying of culture supernatants for TNF by ELISA. Results are comparisons with cytokine production from uninfected cells. There was no significant effect of AdvO infection in (B). All results are representative of at least five different donors.

cartilage destruction in RA. The expression of both MMP-1 and MMP-3 (collagenase-1 and stromelysin) were inhibited by $>60 \%$ on $\mathrm{AdvI} \kappa \mathrm{B} \alpha$ infection (fig $8 \mathrm{~B}$ ). The expression of MMP-13 was less affected (50\%). These data would suggest a role for $\mathrm{NF} \kappa \mathrm{B}$ in the expression of these MMPs. However, a somewhat surprising finding was the observation that the inhibition of NFKB had no effect on the expression of the tissue inhibitor of metalloproteinase 1 (TIMP-1). As for the cytokines, blockade of $\mathrm{NF} \kappa \mathrm{B}$ would seem to provide the optimum result: inhibition of all three of these destructive enzymes, but no effect on their major inhibitor.

\section{Summary}

These studies have demonstrated the potential of using adenoviral vectors for the study of macrophage function in health and disease. The heterogeneous nature of mechanisms controlling TNF production has been demon- strated, with the nature of the stimulus determining the requirement for $\mathrm{NF} \kappa \mathrm{B}$. This result has major implications for future approaches to understanding the mechanisms controlling TNF production in different circumstances. Simple cell models may no longer be sufficient to determine or validate the key signalling pathways in a disease process. Adenoviral vectors can also be used in diseased tissue cultures, like RA synovial cells. In this system, we reproduced the findings that TNF and other proinflammatory cytokines were NFאB dependent, but that IL1RA, IL10 and IL11 were not. Equally importantly, several destructive MMPs were NFKB dependent, but their major endogenous inhibitor was not. These results point out $\mathrm{NF} \kappa \mathrm{B}$ as an important therapeutic target in RA. Therefore, the development and use of more physiologically relevant systems, and the required tools to investigate them, seem necessary for the future
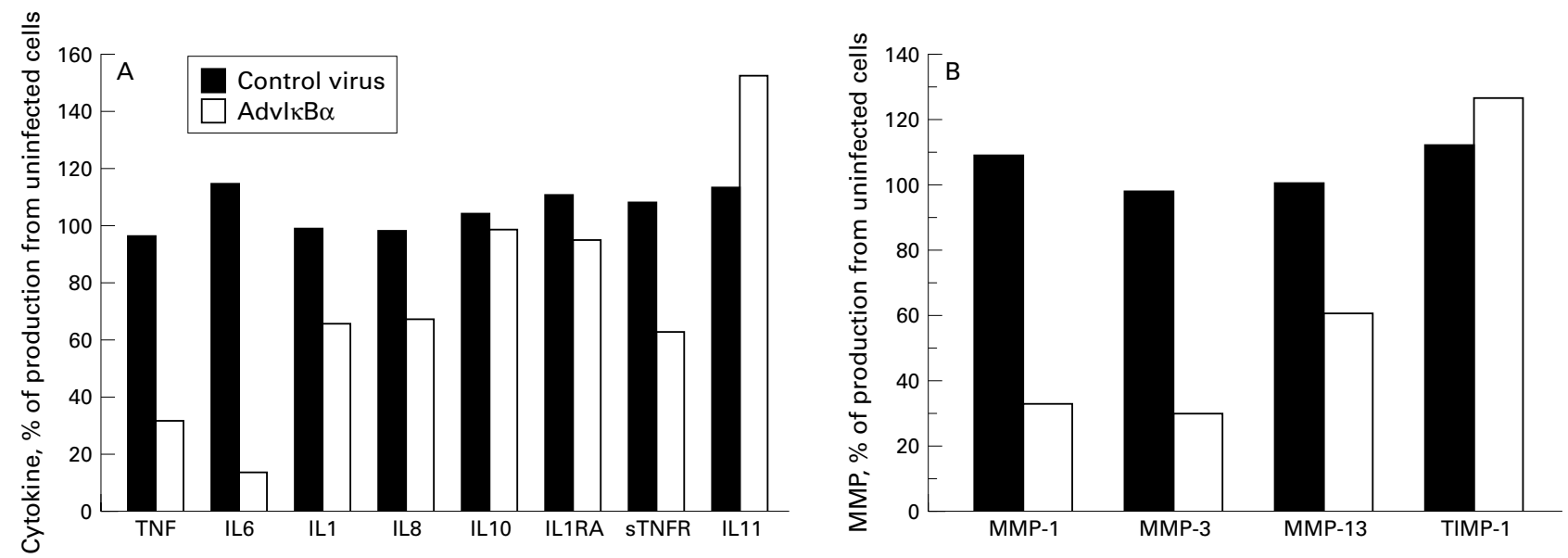

Figure 8 Effect of I $\mathrm{B}$ a transgene on cytokine and MMP expression in RA joint cell cultures. RA joint cells (see fig 5) were infected with AdvI $\mathrm{B}$ a or Adv0 (moi 40). After 48 hours, culture supernatants were harvested and analysed for $(A)$ cytokines and (B) MMPs by ELISA. Data are representative of samples from at least five patients. 
identification of the key molecular mechanisms driving inflammation.

1 Elliott MJ, Maini RN, Feldmann M, et al. Treatment of rheumatoid arthritis with chimeric monoclonal antibodies rheumatoid arthritis with chimeric monoclonal

2 Elliott MJ, Maini RN, Feldmann M, et al. Randomised double blind comparison of a chimaeric monoclonal antibody to tumour necrosis factor $\alpha$ (cA2) versus placebo in rheumatoid arthritis. Lancet 1994;344:1105-10.

3 Rankin ECC, Choy EHS, Kassimos D, et al. The therapeutic effects of an engineered human anti-tumour necrosis factor alpha antibody (CD571) in rheumatoid arthritis. B J Rheumatol 1995;34:334-42.

4 Moreland LW, Baumgartner SW, Schiff MH, et al. Treatment of rheumatoid arthritis with a recombinant human tumor necrosis factor receptor (p75)-Fc fusion protein. N Engl J Med 1997;337:141-7.

5 Feldmann M, Elliott MJ, Woody JN, et al. Anti tumour necrosis factor $\alpha$ therapy of rheumatoid arthritis. Adv Immunol 1997;64:283-350.

6 Maini RN, Breedveld FC, Kalden JR, et al. Therpeutic efficacy of multiple intravenous infusions of anti-tumor necro-
sis factor $\alpha$ monoclonal antibody combined with low-dose sis factor $\alpha$ monoclonal antibody combined with low-dose
weekly methotrexate in rheumatoid arthritis. Arthritis weekly methotrexate in
Rheum 1998;41:1552-63.

7 Maini RN, Taylor PC, Paleolog E, et al. Anti-tumour necrosis factor specific antibody (infliximab) treatment provides insights into the pathophysiology of rheumatoid arthritis. Ann Rheum Dis 1999;58 (suppl 1):I56-60.

8 Feldmann M, Brennan FM, Maini R. Cytokines in autoimmune disorders. Int Rev Immunol 1998;17:217-28.

9 Cope AP, Londei M, Chu NR, et al. Chronic exposure to tumor necrosis factor (TNF) in vitro impairs the activation of $\mathrm{T}$ cells through the $\mathrm{T}$ cell receptor/CD 3 complex; reversal in vivo by anti-TNF antibodies in patients with rheumatoid arthritis. J Clin Invest 1994;94:749-60.

10 Cope AP, Liblau RS, Yang XD, et al. Chronic tumor necrosis factor alters $T$ cell responses by attenuating $T$ cell receptor signaling. J Exp Med 1997;185:1573-84.

11 Shakhov AN, Collart MA, Vassalli P, et al. Kappa B-type enhancers are involved in lipopolysaccharide-mediated transcriptional activation of the tumor necrosis factor alpha transcriptional activation of the tumor necrosis factor alpha
gene in primary macrophages. J Exp Med 1990;171:35-47.

12 Haas M, Page S, Page M, et al. Effect of proteasome inhibitors on monocytic IkappaB-alpha and -beta depletion, tors on monocytic IkappaB-alpha and -beta depletion, NF-kappaB activation,

13 Goldfeld AE, Doyle C, Maniatis T. Human tumor necrosis factor alpha gene regulation by virus and lipopolysaccharide. Proc Natl Acad Sci USA 1990;87:9769-73.

14 McCaffrey PG, Goldfeld AE, Rao A. The role of NFATp in cyclosporin A-sensitive tumor necrosis factor-alpha gene transcription. J Biol Chem 1994;269:30445-50.
15 Tsai EY, Jain J, Pesavento PA, et al. Tumor necrosis factor alpha gene regulation in activated $\mathrm{T}$ cells involves ATF-2/Jun and NFATp. Mol Cell Biol 1996;16:459-67.

16 Han J, Beutler B. The essential role of the UA-rich sequence in endotoxin-induced cachectin/TNF synthesis. Eur Cytokine Netw 1990;1:71-5.

17 Black RA, Rauch CT, Kozlosky CJ, et al. A metalloproteinase disintegrin that releases tumour-necrosis factor-alpha from cells. Nature 1997;385:729-33.

18 Moss ML, Jin SL, Milla ME, et al. Cloning of a disintegrin metalloproteinase that processes precursor tumournecrosis factor-alpha [published erratum appears in Nature 1997 17;386:738]. Nature 1997;385:733-6.

19 Stacey KJ, Ross IL, Hume DA. Electroporation and DNAdependent cell death in murine macrophages. Immunol Cell Biol 1993;71:75-85.

20 Bergelson J M, Cunningham JA, Droguett G, et al. Isolation of a common receptor for Coxsackie $B$ viruses and adenoviruses 2 and 5 . Science 1997;275:1320-3.

21 Huang S, Endo RI, Nemerow GR. Upregulation of integrins alpha $v$ beta 3 and alpha $v$ beta 5 on human monocytes and $\mathrm{T}$ lymphocytes facilitates adenovirus-mediated gene delivery. J Virol 1995;69:2257-63.

22 Haddada H, Lopez M, Martinache C, et al. Efficient adenovirus-mediated gene transfer into human blood monocyte-derived macrophages. Biochem Biophys Res Commun 1993;195:1174-83.

23 Foxwell BMJ, Browne K, Bondeson J, et al. Efficient adenoviral infection with I $\kappa \mathrm{B} \alpha$ reveals that $\mathrm{TNF} \alpha$ production in rheumatoid arthritis is NF- $\mathrm{KB}$ dependent. Proc Natl Acad Sci USA 1998;95:8211-15.

24 Bondeson J, Foxwell B, Brennan F, et al. Defining therapeutic targets by using adenovirus: blocking NF-kappaB inhibits both inflammatory and destructive mechanisms in rheumatoid synovium but spares anti-inflammatory mediators. Proc Natl Acad Sci USA 1999;96:5668-73.

25 Bondeson J, Brown KA, Brennan FM, et al. Selective regulation of cytokine induction by adenoviral gene transfer of I $\mathrm{B} \alpha$ into human macrophages: LPS but not zymosan induced pro-inflammatory cytokines are inhibited, but IL-10 is NF- $\mathrm{KB}$ independent. J Immunol 1999;162:293945

26 Hayes AL, Smith C, Foxwell BM, et al. CD45-induced tumor necrosis factor alpha production in monocytes is phosphatidylinositol 3-kinase-dependent and nuclear factor-kappaB-independent. J Biol Chem 1999;274: 33455-61.

27 Crawley JB, Williams LM, Mander T, et al. Interleukin-10 stimulation of phosphatidylinositol 3-kinase and p70 S6 kinase is required for the proliferative but not the antiinflammatory effects of the cytokine. J Biol Chem $1996 ; 271: 16357-62$. 